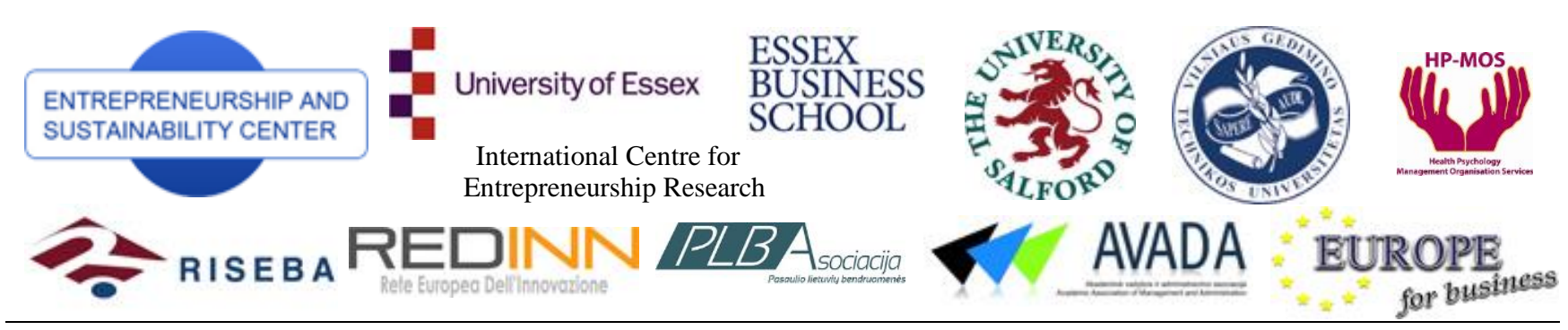

ENTREPRENEURSHIP AND SUSTAINABILITY ISSUES

ISSN 2345-0282 (online) http://jssidoi.org/jesi/aims-and-scope-of-research/

\title{
TOOLS TO SUPPORT SUSTAINABLE ENTREPRENEURSHIP IN ENERGY POSITIVE NEIGHBOURHOODS
}

\author{
Mia Ala-Juusela', Michael Short ${ }^{2}$, Uzi Shvadron ${ }^{3}$ \\ ${ }^{1}$ VTT Technical Research Centre of Finland, Espoo; \\ ${ }^{2}$ Teesside University, $U K$; \\ ${ }^{3}$ IBM Haifa research, Israel

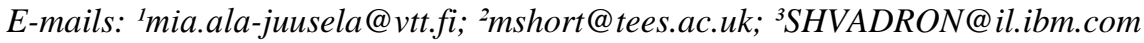 \\ Received 6 September 2014; accepted 28 October 2014
}

\begin{abstract}
In an Energy Positive Neighbourhood (EPN) the annual energy demand is lower than annual energy supply from local renewable energy sources. Short-term imbalances in energy supply and demand are corrected with national energy supplies. In this paper the early stages of the development - the specifications - of the tools for intelligent management of energy positive neighbourhoods are presented. These tools include an energy management tool for real-time management of the energy flows, user interfaces that support energy efficient behavior of the users in the neighbourhood and an urban planning decision support tool. The specifications and tools are the result of European co-operation, and are designed so that they can easily be adopted in different European countries with minimum changes ${ }^{1}$.
\end{abstract}

Keywords: sustainable development, sustainable entrepreneurship, business model, Energy positive neighbourhood, energy management, user interfaces

Reference to this paper should be made as follows: Ala-Juusela, M.; Short, M.; Shvadron, U. 2014. Tools to support sustainable entrepreneurship in energy positive neighbourhoods, Entrepreneurship and Sustainability Issues 2(2): 49-59.

DOI: http://dx.doi.org/10.9770/jesi.2014.2.2(1)

JEL Classifications: M10, Q4

\section{Introduction}

Direction towards sustainable development requires incorporation of renewable energy production and use into economic routine of organizations and households. Alas, this aim is hard to implement to numerous conflicts of economic interests at macro and micro level (Garškaitė-Milvydienė 2012, 2014; Tvaronavičienė 2012; Tvaronavičienė, Grybaite 2012; Balkienė 2013; Miškinis et al. 2013; Mačiulis, Tvaronavičienė 2013; Vosylius et al. 2013; Baublys et al. 2014; Matyasik 2014; Tvaronavičienė 2014; Vasiliūnaitė 2014). Sustainable entrepreneurship in renewable energy sector well-articulated business model (Caurkubule, Rubanovskis 2014; Figurska 2014; Raudeliūnienè et al. 2014; Tarabkova 2014; Peker et al. 2014; Tvaronavičienè et al. 2014).

In an Energy Positive Neighbourhood (EPN) the annual energy demand is lower than energy supply from local renewable energy sources. Short-term imbalances in energy supply and demand are corrected with national energy supplies. The aim is to provide a functional, healthy, user friendly environment with as low energy demand and little environmental impact as possible. (Ala-Juusela et al. 2014) The IDEAS project aims to develop and validate

${ }^{1}$ This work is part of the "IDEAS - Intelligent NeighbourhooD Energy Allocation \& Supervision" project that is funded under the EC's FP7 framework initiative FP7-2012-NMP-ENV-ENERGY-ICT-EeB. Project partners are acknowledged. 
technologies and business models required for the cost effective and incremental rollout of EPNs. The tools for intelligent management of energy positive neighbourhoods include an energy management tool for real-time optimization of the energy balance, user interfaces that support energy efficient behavior of the users in the neighbourhood and an urban planning decision support tool. The technologies and business models developed in IDEAS will underpin the incremental rollout of EPNs at principally two specially selected demonstration sites: part of a University campus in Bordeaux (IUT), France and a newly built residential area (Omenatarha) in Porvoo, Finland. An analysis of the user requirements for stakeholders in an Energy Positive Neighbourhood was conducted in beginning of the project, and the development of the tools and user interfaces are based on this analysis (described by Huovila et al. 2013). They are also the starting point for the business model development. The primary intended user of the tools developed in the IDEAS project is a new type of actor, the energy positive neighbourhood service provider (EPNSP, described in Crosbie et al. 2014). Currently this actor does not exist as such, but is represented in the project by an energy company and a facility manager at the respective demonstration sites, both of which could be the central actor in the business model. In the business model, some key activities are supported by the control and optimisation tools and user interfaces, as well as the decision support tool for urban planning. The neighbourhood energy management tool will enable intelligent energy trading and operation of equipment and buildings along with local energy generation and storage. The user interfaces will use mixed reality technologies to provide intuitive environments that engage casual users and in doing so improve their energy literacy and energy consuming behaviours. The decision support urban planning tool will inform the future development plans for neighbourhood energy infrastructures. It will be used to illustrate how the progress towards energy positive neighbourhoods achieved at the demonstration sites can be further advanced. In addition, in the IDEAS project, appropriate business models for the demonstration cases will be developed, as well as investigating how different utility industry structures and property markets impact on the viability of those business models in different EU countries will be identified. These business models are out of scope for this paper, and the interested reader is referred to Crosbie et al. (2014), where an in-depth analysis of the elements of the business models is provided.

In this paper the early stages of the development - the specifications - of the tools for intelligent management of energy positive neighbourhoods are presented. This is one of the first attempts to balance the energy demand and supply on a neighbourhood level in real time, simultaneously regarding more than one type of energy variable. Innovative ways to involve the users in this activity are developed. Decision support is needed to ensure that the infrastructure of the neighbourhood supports energy positivity: the low local demand connected with possibility for local renewable production. The tools and user interfaces will interact through an Energy Positive Neighbourhood control center (Figure 1).

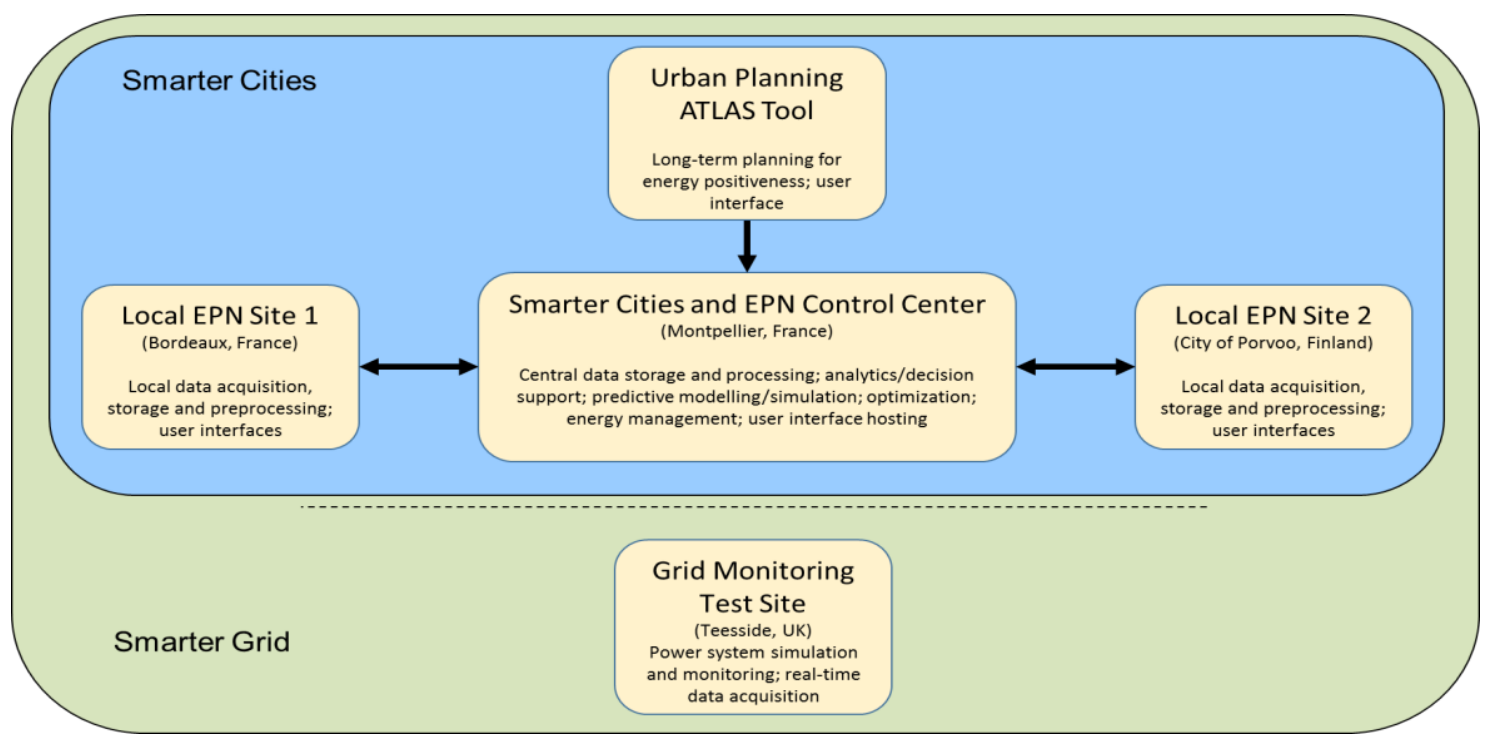

Fig.1. High-level overview of demonstration sites, IT tools and functionalities in the IDEAS project Source: Crosbie et al. (2014) 


\section{Underlying use cases and business models 2.1. Functional use cases for the IDEAS project}

The development of the specifications started with the definition of use cases. A total of 9 functional uses cases have been identified for the IDEAS project, based on the user requirements capture in earlier stages of the project (Huovila et al. 2013). These use cases are listed in Table 1 below2. The use cases were defined in a parallel task for the business model development, which is why the actors appearing in the titles differ slightly from the actors defined in the BMs. The central actor in the business model is an energy positive neighbourhood service provider (EPNSP).

Table 1. List of identified (functional) use-cases in the IDEAS project

\begin{tabular}{|c|c|c|}
\hline ID & Title & Description \\
\hline 1 & $\begin{array}{l}\text { Home Energy Management } \\
\text { (Finnish demo site) }\end{array}$ & $\begin{array}{l}\text { This use case describes how to inform home residents about fine grain } \\
\text { energy consumption in order to help them meet Energy Positive } \\
\text { Neighbourhoods (EPN) energy supply objectives }\end{array}$ \\
\hline 3 & $\begin{array}{l}\text { City Planner Acquires Decision } \\
\text { Support for Energy Aspects in } \\
\text { Urban Planning (Finnish demo } \\
\text { site) }\end{array}$ & $\begin{array}{l}\text { This use case describes how the user of AtLas tool (a city planner in } \\
\text { first place) compares the long term effect of two planning strategies } \\
\text { regarding energy flows on the greenhouse gas emissions, costs and } \\
\text { energy balance }\end{array}$ \\
\hline 4 & $\begin{array}{l}\text { Public Energy Awareness } \\
\text { Interface for residential users }\end{array}$ & $\begin{array}{l}\text { This use case aims to engage residents of Omenatarha (Finnish demo } \\
\text { site) into the Energy Positive Neighbourhood's goals through } \\
\text { awareness feedback of the energy consumption of their (Energy } \\
\text { Positive) Neighbourhood }\end{array}$ \\
\hline 5 & $\begin{array}{l}\text { Decision Support for Energy } \\
\text { Trading for Energy Service } \\
\text { Companies (ESCOs) and } \\
\text { Supply/Demand Regulation } \\
\text { within EPNs (Finnish demo site) }\end{array}$ & $\begin{array}{l}\text { This use case describes how to carry out (i) prediction of future } \\
\text { electrical energy consumption and supply within an EPN and (ii) } \\
\text { optimization of available resources such that operational costs and/or } \\
\mathrm{CO} 2 \text { emissions can be minimized subject to the balancing of supply } \\
\text { with demand }\end{array}$ \\
\hline 6 & $\begin{array}{l}\text { User Interface for Energy Service } \\
\text { Companies (ESCOs) (Finnish } \\
\text { demo site) }\end{array}$ & $\begin{array}{l}\text { Visualising the decision support information for energy trading and } \\
\text { configuration of the optimizer }\end{array}$ \\
\hline 7 & $\begin{array}{l}\text { Facility Manager Acquires } \\
\text { Decision Support on Renovation } \\
\text { Investments' Effect on Energy } \\
\text { Balance of the Neighbourhood } \\
\text { (French demo site) }\end{array}$ & $\begin{array}{l}\text { This use case describes how the user of the AtLas tool (a facility } \\
\text { manger in first place) compares the long term effect of two renovation } \\
\text { investment options on the greenhouse gas emissions, costs and energy } \\
\text { balance }\end{array}$ \\
\hline 8 & $\begin{array}{l}\text { Decision Support for } \\
\text { Supply/Demand Regulation } \\
\text { within EPNs (French demo site) }\end{array}$ & $\begin{array}{l}\text { This use case describes how to carry out (i) prediction of future } \\
\text { electrical energy consumption by the neighbourhood (IUT buildings) } \\
\text { and PV supply potential within the area (IUT campus area) and (ii) } \\
\text { optimization of available resources such that operational costs and/or } \\
\mathrm{CO}_{2} \text { emissions can be minimized through arbitrage and storage, } \\
\text { subject to the balancing of supply with demand }\end{array}$ \\
\hline 9 & $\begin{array}{l}\text { Educational 3D Virtual Space } \\
\text { (French demo site) }\end{array}$ & $\begin{array}{l}\text { This use case describes shared 3D virtual space for demonstrating EPN } \\
\text { concepts to interested visitors (IUT students and others). The idea is to } \\
\text { provide remote visitors with a venue to learn about the IDEAS project, } \\
\text { via an immersive rich collaborative environments without the need to } \\
\text { actually visit the project pilot site }\end{array}$ \\
\hline 10 & $\begin{array}{l}\text { Awareness Tools Dedicated to } \\
\text { Energy Manager and Occupants } \\
\text { of the Site (French demo site) }\end{array}$ & $\begin{array}{l}\text { An interface to better understand how the site consumes energy, } \\
\text { electricity, gas, water to increase occupant awareness about energy and } \\
\text { waste, and to visualise the output of the optimization }\end{array}$ \\
\hline
\end{tabular}

Source: Huovila et al. 2013

\footnotetext{
${ }^{2}$ Please note that use case \#2 does not appear in this list as it was merged with use case \#4; the numbers have been left as-is for traceability and documentation purposes.
} 


\subsection{Business models}

Two versions of the Energy Positive Neighbourhood Service Provider (EPNSP) business models were created in the project (Crosbie et al. 2014): "To realise an EPN it will be necessary to encourage a new type of service provider that offers tailored services which engage whole communities in Demand Side Management (DSM), Supply Side Management (SSM), energy trading, investment in renewable energy production and energy storage and careful consideration of future design options for the urban environment. We have called this new type of service provider an Energy Positive Neighbourhood Service Provider (EPNSP)." The EPNSP business concept developed in the context of the Finnish pilot site involves "an energy company that generates, supplies and distributes electricity and heat from renewable resources in a predominantly residential neighbourhood. The area also includes small commercial customers such as shops and small offices etc. The energy company has a contract to sell electricity and heat with most of the occupants in the Neighbourhood, supplies Demand Side Management (DSM) services to those customers and operates in partnership with the local authority. ... The critical role of the local authority is encouraging investment in the efficient buildings required for an EPN by the occupants' of the neighbourhood and encouraging the occupants of the neighbourhood to connect to the district heating system" (Crosbie et al. 2014).

The EPNSP business concept developed in the French context involves "an energy service company that installs, maintains and runs renewable energy production for a public or private organisation that owns a group of buildings in the same geographical location and is responsible for the energy costs associated with running those buildings. The company also supplies consultancy services to help their customers select the most energy efficient building renovation and energy infrastructure investments and implement and implements building renovations as part of an Integrated Energy Contract (IEC)" (Crosbie et al. 2014). The neighbourhood energy management tool will support the business models in Demand Side Management (DSM), Supply Side Management (SSM) and optimization of energy trading and arbitrage activities in the presence of variable energy market prices. The user interfaces will support the business models in the DSM by informing the customers of when the local renewable supply is available and of expected imbalances in supply and demand, engaging them in the operation of the EPN, and by giving them support in reducing the overall demand. The decision support urban planning tool will support the business models in comparing economic and environmental effects of different future scenarios regarding the urban development and redevelopment and the renewable energy options on the area.

\section{Real-time energy management 3.1. ICT infrastructure}

Achieving EPNs will require co-ordinated and optimised demand side management (DSM) and supply side management (SSM) to reduce and shift peak energy demands and smooth out the inevitable production variability of renewable energy. To facilitate this, a supporting ICT infrastructure that provides a wide variety of interconnectivity options for measurement, control and user interface equipment (e.g. smart meters, synchrophasors, weather measurement stations, grid inverters, building automation controllers, energy trading applications, etc.) is needed. The ICT infrastructure envisions a smarter grid, to enable the buying and selling of energy between prosumers connected via a local grid infrastructure. This grid infrastructure is smart - in that it not only allows for the physical transfer of energy - but also supports ICTs that enable information related to energy supply/demand availability and pricing to be exchanged, along with real-time information related to the health and status of the power flows. The ICT architecture specified in course of the IDEAS project covers three separate domains: (i) the local generation and distribution management domain, (ii) the customer domain and (iii) the web services domain. Relevant standards are leveraged to provide a path towards common data semantics and protocols that may be used across these domains within the context of an EPN. The communications infrastructure required to support smart-grid applications (the so-called 'utility intranet') has not yet been fully developed, but current indications are that it is likely to be based upon IP addressing - to facilitate open interconnectivity - and differentiated services (diffserv) concepts - to support prioritization of traffic flows between real-time, soft realtime and non-real-time classes. This utility intranet is likely to act as the backbone network bridging together local network installations (e.g. control centres, switching- and sub-stations, large generators, microgrids, data concentrators). 
The ICT architecture developed for the IDEAS project covers energy management and control systems at the neighbourhood (microgrid) scale. Building upon the proposals for a larger smart grid ICT infrastructure outlined above, it extends the current state-of-the-art by integrating IEEE Audio-Video-Bridging (AVB) technology to enable reliable real-time and soft real-time data transfers of energy control and management related information over a microgrid Ethernet-over-fibre network. The infrastructure also allows for non-real-time (best-effort) traffic to be carried over the network using standard UCP/IP and TCP/IP over fibre, copper or wireless (WiFi) links, thus allowing services such as smart energy meter reading/aggregation and also information presentation for the main system users using standard protocol stacks. Although not the main focus of the current paper, the interested reader is referred to Short and Dawood (2014a, b) for further details of the low-level real-time aspects of the ICT infrastructure.

The IBMC Intelligent Operations Centre (IOC), with its associated analytics, data warehousing and optimization software, acts as a central platform for the development of the microgrid central control station and data repository. In IDEAS, the IOC is not only the data repository for most data (city and sites data, energy management and urban planning software), but also provides a strong analytics, optimisation and decision support system capability. It provides a host platform for user interfaces, enables stakeholder and partner notifications (via SMS/email and web services), and provides reporting capabilities that can be leveraged by all project partners and used by all end users. With respect to the higher-level, IP-based aspects of the IT infrastructure, please refer to the Figure 2 below. In order to realise and manage the remote interface capabilities required for the demonstrations, the IOC Representational State Transfer (REST) Application Programming Interface (API) will be employed. The REST API may be implemented using a standard HTTP connection via TCP/IP.

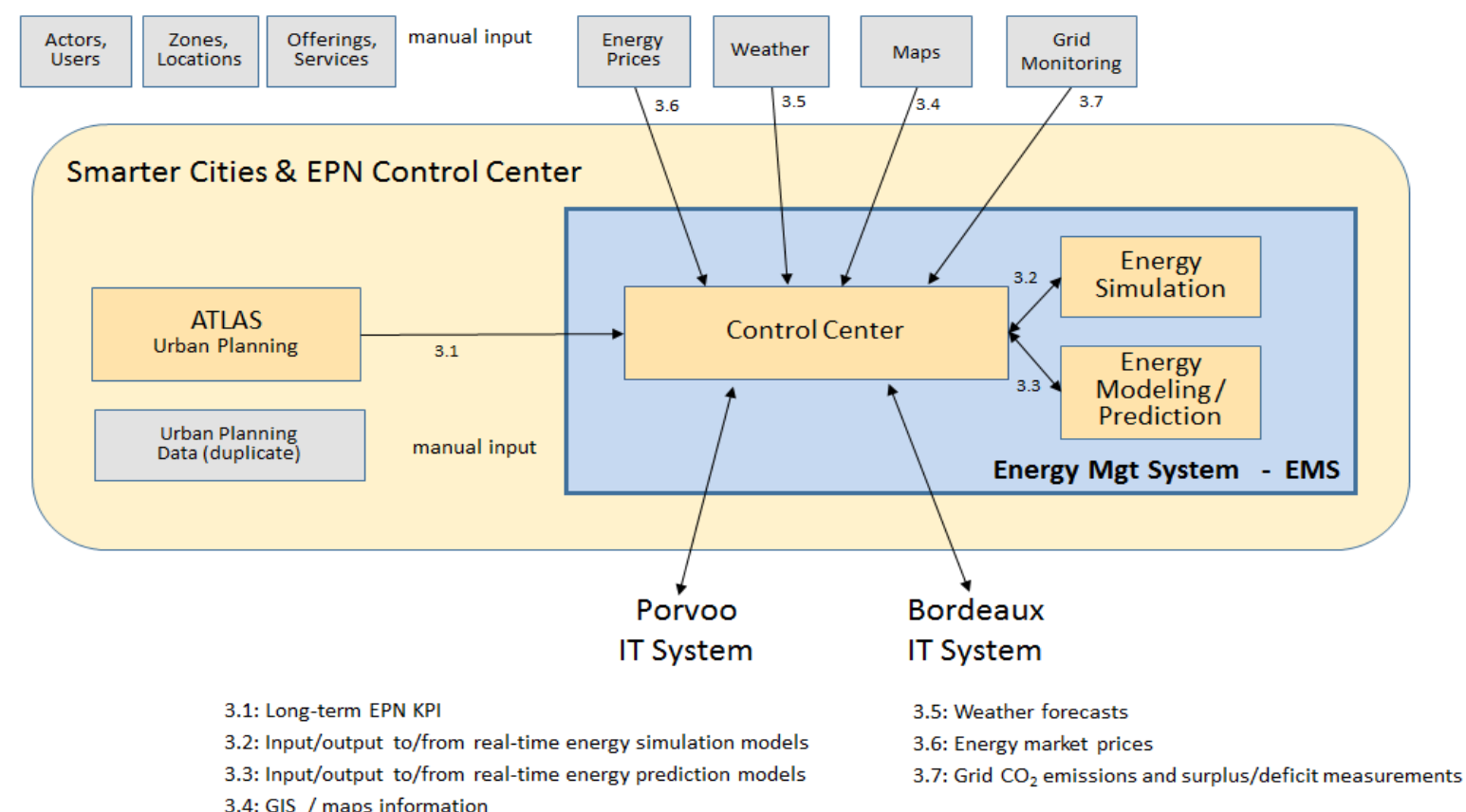

Fig.2. Overview of main IT interfaces

Source: Short and Dawood (2014a, b)

\subsection{Optimisation and support tool}

Again at a generic level, the optimisation and decision support tool provides several main types of operational functionality: (i) adaptive prediction of future energy supply and demand potential, (ii) access to current market conditions and predictions of future market conditions (e.g. energy prices), (iii) receding horizon optimisation to 
balance supply and demand given the market conditions and (iv) additional decision support and dynamic pricing incentives to prosumers and utilities within the EPN.

In terms of building management services and systems such as HVAC, the application of model-based predictive control and optimisation schemes is now known to be beneficial in terms of energy reduction and efficiency improvement potential in both residential and commercial buildings. An enabling step before the application of such schemes is the ability to quickly produce reliable predictions of short-term energy demands. In IDEAS, a novel self-calibrating adaptive demand predictor was specified and is being developed and prototyped. This predictor requires no apriori calibration, and produces predictions of hourly heat and electricity load demands with a mean absolute prediction error (MAPE) increasing from $\approx 1 \%$ for a one-hour ahead prediction to $\approx 5 \%$ for a 24 hour ahead prediction when applied to representative electricity demand data, and increasing from $\approx 2 \%$ for a onehour ahead prediction to $\approx 10 \%$ for a 24 hour ahead prediction when applied to representative heating demand data. Further details of the prediction model specifications may be found in Short et al. (2013). These predictions are repeated at hourly intervals and once obtained, a novel optimisation scheme - based upon the minimization of a linear (weighted) function of economic and $\mathrm{CO} 2$ emissions subject to constraints upon energy storage and generation/availability capacity - can be solved. This finds the optimal plan for balancing supply with predicted demand over a short future horizon of $24 \mathrm{hrs}$. Overall the scheme extends the current state-of-the-art by adapting automatically to changes in the environment through the adaptive prediction models, taking uncertainty into account through the use of a receding horizon and the incorporation of historical prediction errors when adapting the optimization horizon weights, and finally the co-optimization of both heat and electricity within a common framework. An overview of the generic concept is shown in Figure 3 below.

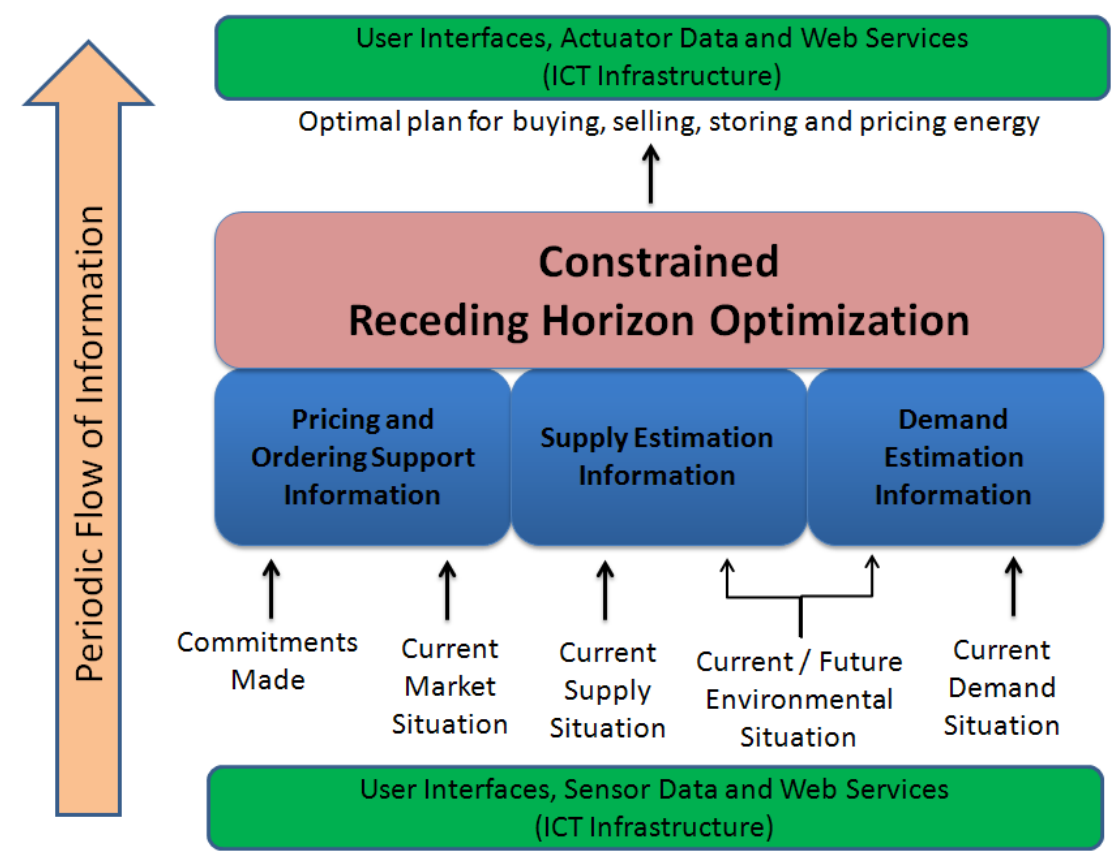

Fig.3. Prediction and Optimization architecture for EPNs

Source: Short et al. (2013)

\section{User interfaces}

The other set of specifications created in the IDEAS project concern the user interfaces. They will be used to create prototype systems to be demonstrated in the two demonstration sites. As such the user interfaces described cover all the aspects of how users in both IDEAS pilot sites can act and what they will experience as a result of those actions. A special user interface is defined for visiting the project in the virtual world site, which will be deployed as part of the French pilot. 


\subsection{Home energy application}

Residents in an EPN need to be aware of their local neighbourhood energy production/consumption so that they can contribute to meeting collective neighbourhood energy positive consumption and production goals. They will not necessarily want to partake in micro energy trading deals, but may be willing to shift their patterns of usage in some cases if they are informed in simple terms that there is an excess or deficit of energy (Shvadron et al. 2013). The research done in the IDEAS project moves beyond the state of the art in energy feedback technologies by using real-time augmented reality technology on hand-held see-through video to give alerts, interact with users and allow them to visualise real-time energy usage of various energy consumption appliances in the home. The user interfaces developed as part of the IDEAS project will inform home residents about fine grain energy consumption of the home appliances and home in general to help them meet Energy Positive Neighbourhood (EPN) energy supply objectives.

To enable this, a user interface has been specified with which the residents of the Finnish demo neighbourhood in Porvoo will be notified by the neighbourhood Energy Management System (EMS) about potential actions that could be taken to reduce peak energy demand and shift energy demand to periods when renewable energy is available. The notifications will be in simple terms and will provide easy to follow actions. A number of appliances or energy consuming devices will be 'tagged' in the home of each resident. An application that runs on a handheld device will show the resident the saving potential of these home appliances and the potential actions that one can take. This Energy Awareness Application (EAA) will make the resident aware of current and historical energy consumption for each appliance. The provided interface is going to be natural even for novice users. The above features will be enabled by installing at home a Home Energy Application (HEA) that will be fed by a smart energy metering system (Shvadron et al. 2013).

To realize the above, a special real-time computer vision environment has been created. It runs novel method for object recognition specially designed for the target appliances at home. This method also enables the augmentation of 2D and 3D graphical objects on the hand held display and provides a natural and clear view of real time information without a need to go through menus or access websites. The information includes notifications on the status of current energy availability that is provided by the central energy management system. The augmentation also provides suggestions of what should be done by the resident per appliance based on the current notification (Figure 4). This novel approach will be tested during the demonstration period.

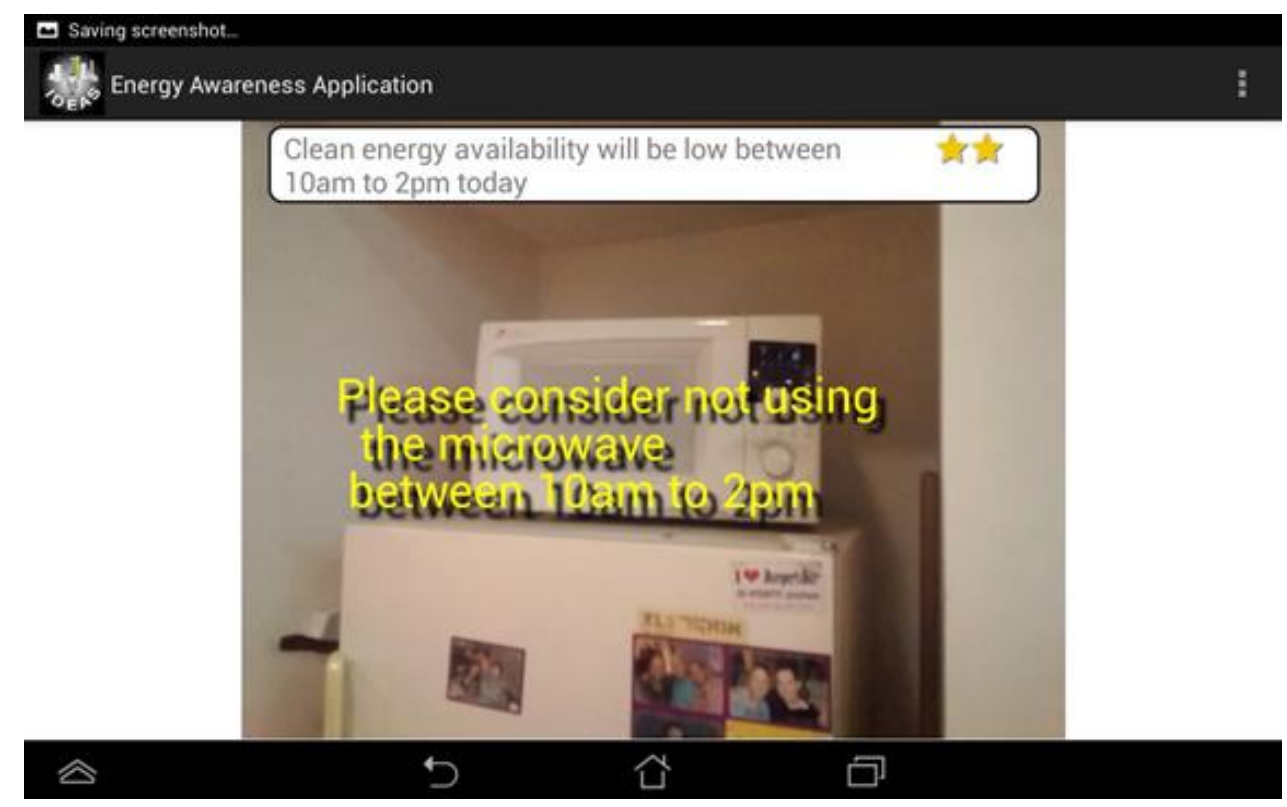

Fig.4. Example of the display of the Energy Awareness Application 


\subsection{D virtual space}

Social interaction within and between communities has a large effect on peoples' behaviour and the uptake and use of technologies and therefore the impact of new technologies on energy demand. The IDEAS project has moved beyond the current state of the art in this area by developing a user interface which is based on mixed reality technology that share publicly accessible 3D virtual space, representing a replica of the IUT demonstration site in Bordeaux, France (Figure 5). The 3D virtual site that has been developed is based on the OpenSim technology. It enables remote users to access the IUT site from anywhere in the world, to be hosted by a local (virtual) person (avatar), and to learn about energy consumption and production options in the site without actually visiting it. The developed system will be connected to the IDEAS energy management system and will show real time energy data of the actual site in the virtual site, such a capability is novel. It will also show simulated energy production data as provided by the EMS.

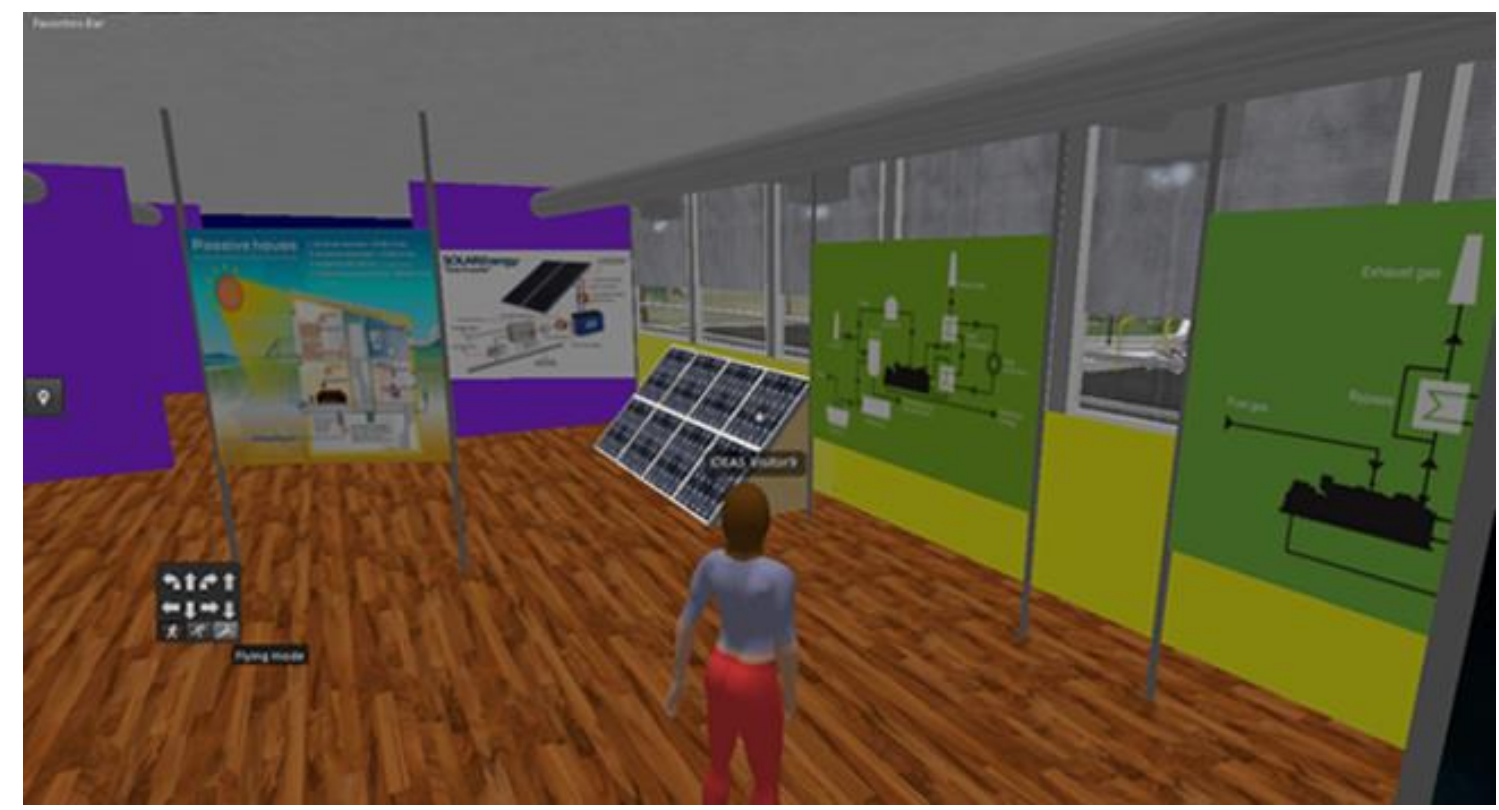

Fig.5. A screen capture from the 3D virtual space

The idea is to provide remote visitors with a virtual venue to learn about the IDEAS project, an immersive rich collaborative environment without the need to actually visit the project pilot site. A unique aspect of the virtual environment is the incorporation of energy production and storage elements into the neighbourhood representation that do not exist in the real sites, and to show how these are integrated into the intelligent management and trading mechanisms developed as part of the project (Shvadron et al. 2013). The 3D virtual site includes also the ability of IUT students to enhance the 3D IUT virtual world with new features and virtual information. This will enable the students to be more involved in the project and give them a chance to add extensions as they see fit to meet new requirements and project capabilities (Shvadron et al. 2013). The 3D virtual space will include models of the equipment that is actually installed in IUT for the IDEAS project. In addition, it may include additional equipment that was not actually installed due to budget restrictions. These may be equipment for energy production, energy storage - where their characteristics and simulation data will be provided by the IDEAS energy management system (Shvadron et al. 2013). The implementation of the 3D virtual site will contribute to efforts to move towards an energy positive neighbourhood at the IUT by enabling anyone to be easily engaged in these efforts. Therefore this interface will enable the concepts of the IDEAS project to be disseminated to many communities and individuals who are interested in energy positive neighbourhoods around the world.

\subsection{Energy awareness screens}

Public screen displays have been designed as part of the project. After a state of the art study on the techniques to improve user engagement through awareness interfaces, these interfaces have been designed to improve Finnish 
stakeholders' engagement on the Finnish pilot site. The main justifications are that residents on the demo site want to be aware of their local neighbourhood energy production/consumption state so that they can contribute their share towards meeting the collective neighbourhood energy positive consumption and production goals. Awareness information will be displayed on three public screens in the nursery school and one at the public info point of the city in order to draw residents' attention. These tactile screens will be located near the entrances of the nursery school in order to allow people to interact with them and to find detailed information. Access will be provided through a web interface both for viewing energy status in the site as well as interaction based on the occupants role. The same display will also be available from any computer so occupants will be able to access the information from home too.

This Energy Awareness interface will make the residents aware of current and historical energy consumption for their neighbourhood. This screen will help the IDEAS project and the City of Porvoo to promote EPN to residents. Wide screen interfaces are based on web technologies and are fed with data provided by the EMS. Based on the previous research for the Finnish pilot site and in order to have coherent interfaces, the wide screens for the French pilot site are based on the same design and structure as the one for the Finnish pilot site. Awareness information will be displayed on 5 screens on the campus in order to draw students and teachers' attention. As it's not possible to use tactile screens, interfaces are going to rotate regularly.

The information will be originally created in English, but will also be presented in local languages on the demo sites (French for IUT site, Finnish and Swedish for the Porvoo site).

\section{Long term energy planning}

This section presents the specifications for a decision support urban planning tool to estimate the economic and environmental effects (e.g. ROI period and CO2-ekv emissions) on different renewable energy supply options and future building developments and redevelopments. The tool evaluates and gives guidance on the possibilities to meet local energy demand with local renewable supply. In addition to supporting the decision making related to the planning of neighbourhood energy networks, the energy positivity indicators produced by the decision support tool will be shown to the users of the neighbourhoods on the public screens mentioned above. To support the development of EPNs an urban planning decision support tool, called AtLas, is under development as part of the IDEAS project. The name of the tool is derived from the Finnish term, Aluetason energia-positiivisuuslaskuri, which roughly translates into energy positivity calculator for neighbourhoods. As part of the later stages of the research the AtLas tool will be tested at the two demonstration sites of the IDEAS project: part of a University campus in Bordeaux (IUT), France and a newly built residential area in Porvoo, Finland (Ala-Juusela et al. 2014). The AtLas tool is a decision support planning tool for use by local planning authorities, energy companies and facilities managers or other EPNSP like actors to support their decision making related to the planning of energy networks for a site or district. The key functionality of the tool is to enable different planning solutions and their long term impact to be quickly and easily compared (Ala-Juusela et al. 2014). The tool will enable the user of the tool (e.g. the Energy Positive Neighbourhood Service Provider, EPNSP) to compare different planning options with regard to the costs and ROI, but also the other aspects contributing to the value proposition, like energy balance and $\mathrm{CO} 2$ emissions of the area. This tool moves beyond the current state of the art as it is more simple to use than currently available tools, it has the ability to function with limited input data and perform calculations over different time periods (i.e. 10 year 20 years and so on). These key requirements and the lack of tools available to meet these requirements were identified as part of the business and community requirements analysis in earlier stages of the project.

The development of the specifications began by defining two use cases for the tool. One in which the user of the AtLas tool (a city planner) compares the long term effect of two planning strategies regarding energy flows on the greenhouse gas emissions, costs and energy balance. The other, in which the user of the AtLas tool (a facility manger) compares the long term effect of two renovation investment options on the greenhouse gas emissions, costs and energy balance (Ala-Juusela et al. 2014). These users represent the central actor of the EPNSP business model at the demonstration sites. The development of the use cases was informed by input from city officials, area planners, energy producers, and energy distributors and facilities managers. As such, the tool's envisaged users 
played a central role in the definition of the future tool's functionality. A review of existing tools used by city planners and facilities managers to support their decision making was also undertaken to inform the specifications by identifying the shortcomings and benefits of existing tools from the user's perspective. Furthermore initial pilot versions of the Atlas tool were demonstrated to users in parallel with the development of the specifications to ensure that the users' requirements are built into the specifications. The major shortcomings that were addressed in the development of the tool include issues with complexity of the existing tools, the required high level of energy and building related knowledge, the lack of site level tools, the transparency of the processes and the lack of time and economic perspective of the existing tools (Ala-Juusela et al. 2014). In addition to supporting the decision making related to the planning of neighbourhood energy networks, the energy positivity indicators produced with the Atlas tool will be shown to the general public at the demonstration sites on the public screens described above. The energy positivity indicators and their calculation are described in more detail by Ala-Juusela et al. (2014).

\section{Conclusions}

ICT tools can support the incremental rollout of EPNs and the key partners of innovative business models to realise this in many different ways. The tools being developed in IDEAS support the key activities of the related business model by enabling the near real time matching of energy demand and supply, engaging the users and public in large to the concept of EPNs and by enabling the comparison of different possible future scenarios for urban renewable deployment.

The specifications and tools are the result of European co-operation, and are designed so that they can easily be adopted in different European countries with minimum changes.

This paper has described the early stages of the tools development in the IDEAS project. Prototypes of these tools have now been developed - based on the specifications presented in this paper - for deployment in the later phases of the research. Currently the project is moving to a demonstration phase, where the tools and user interfaces (as well as elements of the business models) will be tested by real users at the two demonstration sites. Future works by the authors will report the findings of these tests, and evaluate the relative merits and drawbacks of the proposed solutions.

\section{References}

Ala-Juusela, M.; Hradil, P.; Jantunen, J.; Kontio, M.-R.; Ståhlberg, M.; Rosqvist, J.; Rouhiainen, J. and Brassier, P. 2014. Specifications for the urban planning decision support tool. Deliverable 3.4 of IDEAS project.

Balkienè, K. 2013. Sustainable innovativeness: issues and public policy, Journal of Security and Sustainability Issues 3(2): 53-76. DOI: http://dx.doi.org/10.9770/jssi.2013.3.2(5)

Baublys, J.; Miškinis, V.; Konstantinavičiūtè, I.; Lekavičius V. 2014. Aspirations for sustainability and global energy development trends, Journal of Security and Sustainability Issues 3(4): 17-26. DOI: http://dx.doi.org/10.9770/jssi.2014.3.4(2)

Caurkubule, Ž.; Rubanovskis, A. 2014. Sustainable entrepreneurship through motivation: case of Latvian companies, Entrepreneurship and Sustainability Issues 2(1): 43-48. DOI: http://dx.doi.org/10.9770/jesi.2.1(6)

Crosbie, T.; Ye, J.; Short, M.; Thibault, E.; Rosqvist, J.; Brassier, P. and Huovila, A. 2014. Specific business models for demo cases. Deliverable 2.2 of IDEAS project.

Figurska, I. 2014. Sustainable entrepreneurship: localization, acquiring and use of knowledge sources in competitive organization, Entrepreneurship and Sustainability Issues 1(4): 210-222. DOI: http://dx.doi.org/10.9770/jesi.2014.1.4(3)

Garškaitè-Milvydienè, K. 2014. Anti-crisis management of enterprises and possibilities of overcoming their critical condition, Journal of Entrepreneurship and Sustainability Issues 1(4): 187-203. DOI: http://dx.doi.org/10.9770/jesi.2014.1.4(1)

Garškaitè-Milvydienè, K.2012. Diagnostics of bankruptcy threat to enterprises, Journal of Security and Sustainability Issues 1(3): 197203. DOI: http://dx.doi.org/10.9770/jssi/2012.1.3(5) 
Huovila, A.; Jantunen, J.; Ala-Juusela, M.; Sepponen, M.; Tuominen, T.; Thibault, E.; Decorme, R.; Brassier, P.; Rouhiainen, J.; Tuomi, L.; Varis, A.; Ståhlberg, M.; Gras, D. 2013. Business \& community requirements analysis. Deliverable D2.1 of IDEAS project

Mačiulis, A.; Tvaronavičienè, M. 2013. Secure and sustainable development: Lithuania's new role in taking the Presidency of the EU, Journal of Security and Sustainability Issues 3(2): 5-13. DOI: http://dx.doi.org/10.9770/jssi.2013.3.2(1)

Matyasik, M. 2014. Secure sustainable development: impact of social media on political and social crises, Journal of Security and Sustainability Issues 4(1): 5-16. DOI: $\underline{\text { http://dx.doi.org/10.9770/jssi.2014.4.1(1) }}$

Miškinis, V.; Baublys, J.; Lekavičius, V.;Morkvènas, A. 2013. New Changes in Lithuanian Energy Sector, Journal of Security andSustainability Issues 2(3): 15-28. DOI: http://dx.doi.org/10.9770/jssi.2013.2.3(2)

Peker, S.; Tvaronavičienè, M.; Aktan, B. 2014. Sustainable risk management: fuzzy approach to volatility and application on FTSE 100 index, Entrepreneurship and Sustainabillity Issues 2(1): 30-36. DOI: http://dx.doi.org/10.9770/jesi.2014.2.1(4)

Raudeliūnienė, J.; Tvaronavičienè, M.; Dzemyda, I. 2014. Towards economic security and sustainability: key success factors of sustainable entrepreneurship in conditions of global economy, Journal of Security and Sustainability Issues 3(4): 71-79. DOI: http://dx.doi.org/10.9770/jssi.2014.3.4(7)

Short, M.; Dawood, M. 2014a. Networking Infrastructures for Micro Grids Part I: Review and Proposal. To appear in: Proceedings of the International Conference on Green Technology and Sustainable Development 2014 (GTSD'14), Ho Chi Minh City, Vietnam, October 2014.

Short, M.; Dawood, M. 2014b. Networking Infrastructures for Micro Grids Part II: Prototype Architecture and Initial Testing. To appear in: Proceedings of the International Conference on Green Technology and Sustainable Development 2014 (GTSD'14), Ho Chi Minh City, Vietnam, October 2014.

Short, M.; Dawood, M.; Shvadron, U.; Ye, J.; Gras, D.; Ala-Juusela, M. 2013. Specifications for the neighbourhood energy management tool. Deliverable D3.2 of IDEAS project, November 2013.

Shvadron, U.; Short, M.; Gras, D.; Thibault, E.; Brassier, P.; Rosqvist, J.; Ala-Juusela, M. 2013. Specifications for the user interfaces. Deliverable D3.3 of IDEAS project.

Tarabkova, L. 2014. Model of motivating linked-up with education, Entrepreneurship and Sustainability Issues 2(1): 12-18. DOI: http://dx.doi.org/10.9770/jesi.2014.2.1(2)

Tvaronavičienè, M. 2012. Contemporary perceptions of energy security: policy implications, Journal of Security and Sustainability Issues 1(4): 235-247. DOI: http://dx.doi.org/10.9770/jssi.2012.1.4(1)

Tvaronavičienè, M. 2014. If industrial sector development is sustainable: Lithuania compared to the EU, Entrepreneurship and Sustainability Issues 1(3):134-142. DOI: http://dx.doi.org/10.9770/jesi.2014.1.3(2)

Tvaronavičienè, M.; Grybaitè, V. 2012. Sustainable development and performance of institutions: approaches towards measurement, Journal of Security and Sustainability Issues 1(3): 167-175. DOI: http://dx.doi.org/10.9770/jssi/2012.1.3(2)

Tvaronavičienè, $\quad$ M.; $\quad$ Šimelytè, $\quad$ A., $\quad$ Lace, $\quad$ N. $\quad 2014 . \quad$ Sustainable development facets: exporting industrial sectors from inside, Journal of Security and Sustainability Issues 3(4): 37-44. DOI: http://dx.doi.org/10.9770/jssi.2014.3.4(4)

Vasiliūnaitè, R. 2014. Sustainable development: methodological approaches toward issues, Journal of Security and Sustainability Issues 3(3): 69-75. DOI: http://dx.doi.org/10.9770/jssi.2014.3.3(6)

Vosylius, E.; Rakutis, V.; Tvaronavičienè, M. 2013. Economic growth, sustainable development and energy security interrelation, Journal of Security and Sustainability Issues 2(3): 5-14. DOI: http://dx.doi.org/10.9770/jssi.2013.2.3(1)

This is an open access journal and all published articles are licensed under a Creative Commons Attribution 4.0 International License 